\title{
Almond supplementation reduces serum uric acid in coronary artery disease patients: a randomized controlled trial
}

\author{
Humaira Jamshed ${ }^{1}$, Anwar-ul-Hassan Gilani ${ }^{1,2 *}$, Fateh Ali Tipoo Sultan³, Faridah Amin ${ }^{1}$, Jamshed Arslan1, \\ Sumaira Ghani ${ }^{1}$ and Madiha Masroor ${ }^{1}$
}

\begin{abstract}
Objective: Elevated serum uric acid (UA), a biomarker of renal insufficiency, is also an independent prognostic marker for morbidity in coronary artery disease (CAD) and poses serious health risks. This study reports the effect of almond consumption on UA in CAD patients.

Study design: A randomized controlled clinical trial was conducted with three groups: no-intervention (NI), Pakistani almonds (PA) or American almonds (AA). Patients were recruited from the Cardiology Clinics, Aga Khan University Hospital. Two follow-ups were scheduled at week-6 and week-12. 150 patients were randomly divided in three groups (50 per group). NI was not given almonds, whereas the PA and AA were given Pakistani and American almond varieties (10 $\mathrm{g} /$ day), respectively; with instruction to soak overnight and eat before breakfast.

Results: Almonds supplementation significantly reduced $(p<0.05)$ serum $\cup A$ among groups, and over time. At week-6, UA concentrations were -13 to $-16 \%$ less in PA and AA; at week-12 the concentrations were -14 to $-18 \%$ less, compared to NI. Systolic and diastolic blood pressure and body weights of the participants remained fairly constant among all the groups.

Conclusion: Almonds (10 g/day), eaten before breakfast, reduces serum UA in CAD patients. Prevention of hyperuricemia can confer protection from kidney and vascular damage and if extrapolated for general population, dietary almonds can offer grander health benefit. Trial is registered at Australian New Zealand Clinical trial registry as ACTRN12614000036617.
\end{abstract}

Keywords: Hyperuricemia, Coronary artery disease, Nuts, Soaked almonds, Low dose

\section{Introduction}

There has been considerable increase in global prevalence of hyperuricemia, in the past few years, backed by western dietary patterns. Where higher serum uric acid (UA) frequently indicates renal insufficiency [1], it may also be associated with coronary artery disease (CAD) [2], and deliberated as a prognostic marker for morbidity and mortality, independent of other risk factors [3]. Even in patients with no history of heart disease or stroke, elevated UA was associated with higher risk of myocardial

\footnotetext{
* Correspondence: anwar.gilani@aku.edu; anwarhgilani@yahoo.com ${ }^{1}$ Department of Biological and Biomedical Sciences, Aga Khan University, Karachi, Pakistan

${ }^{2}$ Pakistan Council for Science and Technology, Government of Pakistan, Shahara-i-Jamhuriat, G-5/2, Islamabad, Pakistan

Full list of author information is available at the end of the article
}

infarction or stroke [4]. An increase in serum UA by $1 \mathrm{mg} / \mathrm{dL}$ contributes to $12 \%$ increase in risk of CAD death [5]. This association is believed to be stronger in women than men [5]. But there are also some indications where, in middle-aged men, hyperuricemia served as a risk factor for cardiovascular and all-cause mortality [6].

UA is shown to possess anti-oxidant potential [7], which undermines its causative role in chronic diseases. Yet, its establishment as a comorbid risk marker is backed by recent meta-analysis [8] and systemic review [5] showing significant correlation between hyperuricemia and CAD. Further signifying its role for cardiovascular health, are the studies where anti-hypertensive and/or lipidneutralizing therapies limited UA production, thereby reducing CAD mortality $[9,10]$. 
Almonds are among the nuts approved by Food and Drug Administration - United States to have the potential of reducing CVD risk [11]. The lipid-neutralizing properties, among others, have been extensively elaborated [12]. Dietary supplementation of almonds is shown to prevent hyperuricemia in a cardiovascular disease rat model [13]. This study inspects the UA-reducing potential of almond supplementation in CAD patients.

\section{Methods}

\section{Study population}

Hundred and fifty CAD patients were recruited from Cardiology Clinic at The Aga Khan University Hospital, Karachi. The eligibility criteria and trial logistics have previously been defined in detail, following the CONSORT guidelines [14]. Briefly, patients consuming nuts on regular basis ( $>15 \mathrm{~g} / \mathrm{d}$; three days/week) or those having nut allergies were excluded. Informed consent was obtained. Using block randomization, patients were assigned any of the following three groups: No Intervention (NI); Intervention with Pakistani almonds (PA) or American almonds (AA).

\section{Study design}

Approval was obtained from Ethical Review Committee of The Aga Khan University, Karachi, Pakistan (Application ID: 2230-Med-ERC-12), and the trial was registered at Australian New Zealand Clinical Trial Registry (ID: ACTRN12614000036617).

Baseline blood was drawn and vitals (body weight, blood pressure etc.) were recorded. Participants of NI were instructed not to consume any nuts, specifically almonds, during their enrollment in trial; whereas participants of PA and AA were given almonds (10 g/day), with the instruction to consume in a traditional way (i.e. soak overnight, peel and eat before breakfast in the morning). Diaries, to record almond consumption, were provided. Compliance was monitored through regular phone calls (twice per week). Follow-up visits were scheduled at week- 6 and week-12 ( \pm 3 days), at which blood samples were collected and vitals were recorded. Participants of NI received almonds after the completion of trial.

Pakistani almonds, namely Talwar, grown in Balochistan Pakistan; and imported American almonds, locally available at Utility stores in Karachi, were used. Serum concentration of uric acid (UA) was measured on Roche Cobass c-111 automated analyzer using commercially available kit (Uric acid kit no. 4657608190).

Data were analyzed on SPSS version 17.0 and Graphpad Prism, and results are presented as means \pm SEM. Twoway repeated measures ANOVA was used to compare means of groups followed by Bonferroni post-tests. For categorical data, chi-square test was used to compare differences between groups. $P$-value $<0.05$ was considered statistically significant (95\% Confidence interval).

\section{Results}

The flow of participants through the trial, as per CONSORT format, has been reported previously [14]. Attrition rate was around $15 \%$. The major reasons included: failure to contact $(n=20)$; leaving city in summer vacations $(n=8)$; and a few cases of angioplasty $(n=3)$. The baseline characteristics of participants in each group, is provided in Table 1. Systolic and diastolic BP and body weight of the participants remained fairly constant $(p>0.05)$ throughout the twelve weeks of the study, as seen in Table 2.

Serum UA concentrations were similar at baseline (Table 1$)$, in all the groups $(p>0.05)$. In a male-to-male and female-to-female comparison, the data in Table 2 show that in PA group, at week- 6 , males had $-15 \%$ and females had $-12 \%$ lower UA than those in NI $(p<0.05)$.

Table 1 Baseline characteristics of CAD patients randomized into no-intervention, Pakistani almond or American almond groups

\begin{tabular}{|c|c|c|c|c|c|c|}
\hline & \multicolumn{2}{|c|}{ No Intervention ${ }^{1}$} & \multicolumn{2}{|c|}{ Pakistani Almonds ${ }^{1}$} & \multicolumn{2}{|c|}{ American Almonds ${ }^{1}$} \\
\hline & Mean & SEM & Mean & SEM & Mean & SEM \\
\hline Age, years & 61 & 0.2 & 57 & 1.6 & 61 & 1.5 \\
\hline \multicolumn{7}{|l|}{ Gender } \\
\hline Male, $n$ & 39 & & 36 & & 38 & \\
\hline Female, $n$ & 11 & & 14 & & 12 & \\
\hline Body weight, kg & 73.4 & 0.2 & 79 & 1.9 & 75 & 1.6 \\
\hline \multicolumn{7}{|c|}{ Blood Pressure, mmHg } \\
\hline Systolic & 127 & 0.4 & 126 & 2.4 & 128 & 2.6 \\
\hline Diastolic & 70 & 0.2 & 67 & 1.2 & 68 & 1.3 \\
\hline \multicolumn{7}{|c|}{ Serum Uric Acid, mg/dL } \\
\hline Male & 7.2 & 0.49 & 6.9 & 0.23 & 6.8 & 0.22 \\
\hline Female & 5.9 & 0.34 & 5.7 & 0.14 & 5.6 & 0.21 \\
\hline
\end{tabular}

${ }^{1} n=50$ per group 
Table 2 Blood pressure and serum uric acid concentrations of CAD patients randomized into no-intervention (NI), Pakistani almonds (PA) and American Almonds (AA) groups, at week-6 and week 12

\begin{tabular}{|c|c|c|c|c|c|c|c|c|c|c|c|c|c|}
\hline & & \multicolumn{4}{|c|}{ No Intervention } & \multicolumn{4}{|c|}{ Pakistani Almonds } & \multicolumn{4}{|c|}{ American Almonds } \\
\hline & & \multicolumn{2}{|l|}{$\begin{array}{l}\text { Male } \\
n=25\end{array}$} & \multicolumn{2}{|c|}{$\begin{array}{l}\text { Female } \\
n=9\end{array}$} & \multicolumn{2}{|l|}{$\begin{array}{l}\text { Male } \\
n=27\end{array}$} & \multicolumn{2}{|c|}{$\begin{array}{l}\text { Female } \\
n=11\end{array}$} & \multicolumn{2}{|l|}{$\begin{array}{l}\text { Male } \\
n=33\end{array}$} & \multicolumn{2}{|c|}{$\begin{array}{l}\text { Female } \\
n=8\end{array}$} \\
\hline & & Mean & SEM & Mean & SEM & Mean & SEM & Mean & SEM & Mean & SEM & Mean & SEM \\
\hline \multicolumn{14}{|l|}{ Blood Pressure } \\
\hline \multirow[t]{2}{*}{ Systolic, mmHg } & Week 6 & 128 & 0.5 & 129 & 0.6 & 126 & 1.7 & 127 & 0.9 & 127 & 1.7 & 126 & 1.4 \\
\hline & Week 12 & 126 & 1.2 & 127 & 0.5 & 124 & 3.1 & 126 & 1.2 & 125 & 3.4 & 125 & 0.5 \\
\hline \multirow[t]{2}{*}{ Diastolic, mmHg } & Week 6 & 71 & 0.3 & 69 & 0.4 & 67 & 0.5 & 68 & 0.5 & 67 & 0.2 & 66 & 0.8 \\
\hline & Week 12 & 70 & 1.8 & 69 & 1.0 & 66 & 1.2 & 67 & 1.1 & 67 & 1.0 & 67 & 0.2 \\
\hline \multirow[t]{2}{*}{ Uric Acid, mg/dL } & Week 6 & 7.1 & 0.2 & 5.8 & 0.17 & $6.0^{*}$ & 0.22 & $5.1^{*}$ & 0.16 & $5.9^{*}$ & 0.26 & $4.7^{*}$ & 0.26 \\
\hline & Week 12 & 7.0 & 0.3 & 5.8 & 0.25 & $5.8^{*}$ & 0.20 & $4.9^{*}$ & 0.15 & $5.6^{*}$ & 0.28 & $4.6^{*}$ & 0.27 \\
\hline
\end{tabular}

At week-12, male and female participants of PA had -17 and $-16 \%$ lower concentrations, respectively, those in NI $(p<0.05)$. Table 2 also shows that, at week-6, serum $\mathrm{UA}$ in male and female participants of AA were -17 and $-19 \%$ less than in NI $(p<0.05)$. At week-12, UA was further reduced up to -20 and $-21 \%$ in males and females, respectively, in AA.

Figure 1a shows comparison with respect to baseline. At week-6, drop in serum UA concentration in male $(1 \%)$ and female $(2 \%)$ participants of NI was insignificant $(p>0.05)$. In the almonds-intervention groups, there was a significant $(p<0.05)$ drop in UA; around $-13 \%$ in males of both PA and AA, and -11 and $-16 \%$ in females of PA and AA, respectively.

Figure $1 \mathrm{~b}$ compares UA concentrations of baseline and intervention. At week-12, there was negligible (-3 and $-2 \%)$ drop in males and females of NI, while the drop in PA and AA was significant $(-16$ and $-14 \%$ in males and females of PA and $-18 \%$ in both males and females of AA; $p<0.05$ ).

\section{Discussion}

To the best of our knowledge, this is the first almondintervention study on CAD patients reporting UA reduction. Previously, in rat model, dietary almonds prevented high-fat diet-induced hyperuricemia, followed by reduced nitric oxide $(\mathrm{NO})$ production via endothelial $\mathrm{NO}$ synthase (eNOS) inhibition resulting in improved vascular function of isolated aorta [13]. So, from results in CAD patients, we can also infer probable vascular protection.

Serum UA may be considered as a biomarker for vascular function [15]. Anticipated pathways of UA-induced vascular dysfunction [16] include, but are not limited to: pro-oxidative affect, whereby UA decomposes and generates free radicals; pro-inflammatory affect via association with biomarkers like interleukins (IL-1, IL-6, IL-10, IL-18), tumor necrosis factor (TNF- $\alpha$ ) and C-reactive proteins (CRP); endogenous stimulation of innate immunity; changing expression of endothelin-1; promoting angiotensin-II production; inducing smooth muscle cell proliferation; and direct reaction with, and depletion of NO.

Almond supplementation is shown to influence some of these parameters. Although, Jenkins et al. report no effect of almonds on CRP, BP or pulmonary NO [17]; Rajaram et al. [18] observed significant reduction in CRP. Two studies in diabetic patients $[19,20]$, report a drop in CRP accompanied by anti-inflammation via IL-6

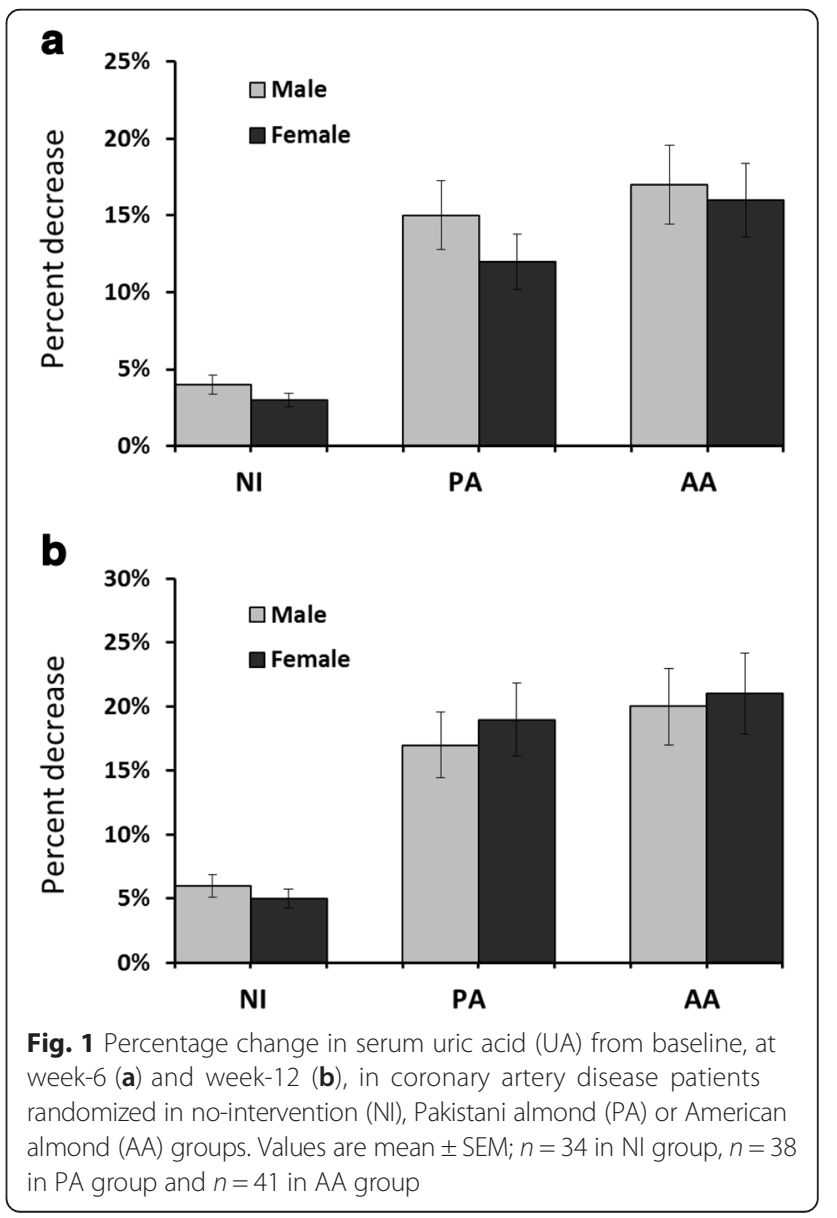


reduction; while Liu et al. [20], also reports decrease in TNF- $\alpha$ by dietary almonds. Bhardwaj et al. [21], also demonstrated drop in CRP, accompanied by improved flowmediated dilatation, indicating improved endothelial function. But more recently, Chen et al. [22] reported no effect of almond supplementation on vascular function, CRP, TNF- $\alpha$ and even the lipid profile of CAD patients in a randomized cross-over clinical trial. This may be due to the drug therapy which could mimic the effect of intervention. Decrease in vascular cell adhesion molecules was observe, which may indicate improvement in vascular function. Trials longer than four to six weeks may be able to offer detectible improvements in vascular function of $C A D$ patients.

Almonds are rich in L-arginine, which is a precursor of NO. Supplementation of L-synthetic arginine reverses hyperuricemia-induced hypertension in rats [23]. However, BP of participants in our trial remained fairly constant during twelve weeks. Reason being, almost all CAD patients were on anti-hypertensive medications, and baseline $\mathrm{BP}$ was within normal ranges.

The precise underling mechanisms of almonds action on serum uric acid remains to be explored. Certain limitations of our trial include the following. The inclusion criteria included only those CAD patients, who had optimal LDL-C and sub-optimal HDL-C. This may not truly represent the CAD population in general. Sample size was calculated for observable improvements in serum HDL.

\section{Conclusion}

Almond supplementation can provide holistic benefits to CAD patients. Previous clinical studies have almonds' potential in ameliorating dyslipidemia, the current investigation adds to its vasculo-protective effects, by presenting prominent reduction in serum uric acid.

\footnotetext{
Abbreviations

$\mathrm{AA}$, American almonds; $\mathrm{BP}$, blood pressure; $\mathrm{CAD}$, coronary artery disease; $\mathrm{CVD}$, cardiovascular diseases; NI, no intervention; NO, nitric oxide; PA, Pakistani almonds; UA, uric acid
}

\section{Funding}

This study was supported by the Higher Education Commission through Indigenous PhD scholarship grant. The Higher Education Commission had no role in the design, analysis or writing of this article.

\section{Availability of data and materials}

The data supporting the conclusions of this article are included within the article (table and figure).

\section{Authors' contributions}

AHG designed and guided research (project conception, development of overall research plan, and study oversight). HJ conducted research (hands-on conduct of the experiments and data collection) and analyzed the data and drafted the manuscript. FATS was the primary Cardiologist involved in dealing with patients. FA helped in designing of the clinical trial and statistical analysis. $J A$, SG and MM were involved in patients' recruitment and maintaining follow-up visits, blood collection, processing and preservation. AHG, FATS and JA helped in refining the manuscript. All authors have read and approved the final manuscript.

\section{Competing interests}

The authors declare that they have no competing interests.

\section{Consent for publication}

The written informed consent signed by all the participants, also included the consent for publication.

\section{Ethical approval and consent to participate}

This study was conducted according to the guidelines laid down in the Declaration of Helsinki and all procedures involving human patients were approved by the Ethics Review Committee, Aga Khan University (Application ID: 2230-Med-ERC-12). Written informed consent (in both languages i.e. English and Urdu) was obtained from all patients.

\section{Author details}

${ }^{1}$ Department of Biological and Biomedical Sciences, Aga Khan University, Karachi, Pakistan. ${ }^{2}$ Pakistan Council for Science and Technology, Government of Pakistan, Shahara-i-Jamhuriat, G-5/2, Islamabad, Pakistan. ${ }^{3}$ Department of Medicine, Aga Khan University, Karachi, Pakistan.

Received: 28 March 2016 Accepted: 2 August 2016

Published online: 19 August 2016

\section{References}

1. Obermayr RP, Temml C, Gutjahr G, Knechtelsdorfer M, Oberbauer R, KlauserBraun R. Elevated uric acid increases the risk for kidney disease. J Am Soc Nephrol. 2008:19:2407-13.

2. Moriarity JT, Folsom AR, Iribarren C, Nieto FJ, Rosamond WD. Serum uric acid and risk of coronary heart disease: atherosclerosis risk in communities (ARIC) study. Ann Epidemiol. 2000;10:136-43.

3. Isik T, Ayhan E, Ergelen M, Uyarel H. Uric acid: a novel prognostic marker for cardiovascular disease. Int J Cardiol. 2012;156:328-9.

4. Bos MJ, Koudstaal PJ, Hofman A, Witteman JC, Breteler MM. Uric acid is a risk factor for myocardial infarction and stroke the Rotterdam study. Stroke. 2006;37:1503-7.

5. Kim SY, Guevara JP, Kim KM, Choi HK, Heitjan DF, Albert DA. Hyperuricemia and coronary heart disease: a systematic review and meta-analysis. Arthritis Care Res. 2010;62:170-80.

6. Fang J, Alderman MH. Serum uric acid and cardiovascular mortality: the NHANES I epidemiologic follow-up study, 1971-1992. JAMA. 2000;283:2404-10

7. Nieto FJ, Iribarren C, Gross MD, Comstock GW, Cutler RG. Uric acid and serum antioxidant capacity: a reaction to atherosclerosis? Atherosclerosis. 2000:148:131-9.

8. Wheeler JG, Juzwishin KD, Eiriksdottir G, Gudnason V, Danesh J. Serum uric acid and coronary heart disease in 9,458 incident cases and 155,084 controls: prospective study and meta-analysis. PLoS Med. 2005;2:236.

9. Athyros VG, Mikhailidis DP, Liberopoulos EN, Kakafika Al, Karagiannis A, Papageorgiou AA, Tziomalos K, Ganotakis ES, Elisaf M. Effect of statin treatment on renal function and serum uric acid levels and their relation to vascular events in patients with coronary heart disease and metabolic syndrome a subgroup analysis of the GREek atorvastatin and coronary heart disease evaluation (GREACE) study. Nephrol Dial Transplant. 2007;22:118-27.

10. Song $Q$, et al. Impact of allopurinol on heart function, endothelial function and indexes of inflammation in patients with acute myocardial infarction. China Pharmacy. 2006;24:018.

11. Ternus $\mathrm{M}$, et al. Qualified health claim for nuts and heart disease prevention: development of consumer-friendly language. Nutr Today. 2006;41:62-6.

12. Berryman CE, Preston AG, Karmally W, Deckelbaum RJ, Kris-Etherton PM. Effects of almond consumption on the reduction of LDL-cholesterol: a discussion of potential mechanisms and future research directions. Nutr Rev. 2011:69:171-85.

13. Jamshed H, Gilani AH. Almonds inhibit dyslipidemia and vascular dysfunction in rats through multiple pathways. J Nutr. 2014;144:1768-74.

14. Jamshed $H$, Sultan FA, Iqbal $R$, Gilani AH. Dietary almonds increase serum $\mathrm{HDL}$ cholesterol in coronary artery disease patients in a randomized controlled trial. J Nutr. 2015;145:2287-92. 
15. Jamshed H, Arslan J, Gilani AH. Cholesterol-cholate-butterfat diet offers multi-organ dysfunction in rats. Lipids Health Dis. 2014;13:194.

16. Johnson RJ, Kang DH, Feig D, Kivlighn S, Kanellis J, Watanabe S, Tuttle KR, Rodriquez-Iturbe B, Herrera-Acosta J, Mazzali M. Is there a pathogenetic role for uric acid in hypertension and cardiovascular and renal disease? Hypertension. 2003:41:1183-90.

17. Jenkins DJ, Kendall CW, Marchie A, Parker TL, Connelly PW, Qian W, Haight JS, Faulkner D, Vidgen E, Lapsley KG, Spiller GA. Dose response of almonds on coronary heart disease risk factors: blood lipids, oxidized low-density lipoproteins, lipoprotein (a), homocysteine, and pulmonary nitric oxide a randomized, controlled, crossover trial. Circulation. 2002;106:1327-32.

18. Rajaram S, Connell KM, Joan S. Effect of almond-enriched high-monounsaturated fat diet on selected markers of inflammation: a randomised, controlled, crossover study. Br J Nutr. 2010;103:907-12.

19. Sweazea KL, Johnston CS, Ricklefs KD, Petersen KN. Almond supplementation in the absence of dietary advice significantly reduces $\mathrm{C}$-reactive protein in subjects with type 2 diabetes. J Funct Foods. 2014;10:252-9.

20. Liu JF, et al. The effect of almonds on inflammation and oxidative stress in Chinese patients with type 2 diabetes mellitus: a randomized crossover controlled feeding trial. Eur J Nutr. 2013;52:927-35.

21. Bhardwaj R, Manivannan S, Gharib W, Warden B, Hobbs G, Jain A. Acute effects of diets rich in almonds and walnuts on endothelial function in humans. Circulation. 2012;126:A14738.

22. Chen CY, Holbrook M, Duess MA, Dohadwala MM, Hamburg NM, Asztalos BF, Milbury PE, Blumberg JB, Vita JA. Effect of almond consumption on vascular function in patients with coronary artery disease: a randomized, controlled, cross-over trial. Nutr J. 2015;14:61.

23. Sánchez-Lozada LG, Tapia E, López-Molina R, Nepomuceno T, Soto V, AvilaCasado C, Nakagawa T, Johnson RJ, Herrera-Acosta J, Franco M. Effects of acute and chronic L-arginine treatment in experimental hyperuricemia. Am J Physiol-Renal Physiol. 2007;292:1238-44.

\section{Submit your next manuscript to BioMed Central and we will help you at every step:}

- We accept pre-submission inquiries

- Our selector tool helps you to find the most relevant journal

- We provide round the clock customer support

- Convenient online submission

- Thorough peer review

- Inclusion in PubMed and all major indexing services

- Maximum visibility for your research

Submit your manuscript at www.biomedcentral.com/submit

C Biomed Central 